\title{
Downregulation of importin-9 protects MCF-7 cells against apoptosis induced by the combination of garlic-derived alliin and paclitaxel
}

\author{
MAGDALENA IZDEBSKA $^{1 *}$, DARIUSZ GRZANKA $^{2 *}$, MACIEJ GAGAT $^{1}$, \\ MARTA HAŁAS-WIŚNIEWSKA ${ }^{1}$ and ALINA GRZANKA ${ }^{1}$
}

\begin{abstract}
${ }^{1}$ Department of Histology and Embryology, and ${ }^{2}$ Department and Clinic of Dermatology, Sexually Transmitted Diseases and Immunodermatology, Nicolaus Copernicus University in Torun, Collegium Medicum in Bydgoszcz, Faculty of Medicine, 85-092 Bydgoszcz, Poland
\end{abstract}

Received November 23, 2015; Accepted January 11, 2016

DOI: $10.3892 /$ or.2016.4628

\begin{abstract}
Numerous studies on the biological mechanism of breast cancer have identified a number of potential therapeutic molecular targets. In this context, one type of potential candidates appears to be agents that target the actin cytoskeleton of cancer cells or regulate actin cytoskeleton dynamics. The aim of the present study was to study the impact of altered actin transport between the cytoplasm and nucleus by the downregulation of importin-9 (IPO9) in breast adenocarcinoma MCF-7 cells exposed to an apoptosis-inducing combination of garlic-derived S-allyl-L-cysteine sulfoxide (alliin) and paclitaxel (PTX). The expression of IPO9 was downregulated by the transfection of non-aggressive breast cancer MCF-7 cells with siRNA against IPO9. The altered expression of IPO9 and cofilin-1 (CFL1) was examined using western blotting. Moreover, the effect of the downregulation of IPO9 on cell death induced by the combination of PTX and alliin was also investigated. The alterations of IPO9 and CFL1 levels were also related with F-actin organizational changes and F-actin fluorescence intensity in the nuclear/perinuclear area of the cells. The results presented here indicate that alliin and PTX act synergistically to promote and potentiate apoptosis in MCF-7 cells. Furthermore, using RNA interference technique, we showed that downregulation of IPO9 expression was correlated with a significant reduction in the apoptotic cell population as well as with a decrease in F-actin content in
\end{abstract}

Correspondence to: Dr Maciej Gagat, Department of Histology and Embryology, Nicolaus Copernicus University in Torun, Collegium Medicum in Bydgoszcz, Faculty of Medicine, Karłowicza 24, 85-092 Bydgoszcz, Poland

E-mail: mgagat@cm.umk.pl

*Contributed equally

Key words: MCF-7 cells, F-actin, importin-9, cofilin-1, siRNA, RNAi, paclitaxel, alliin, cell death whole cells, and in the cortical and nuclear/perinuclear areas of the cells. Simultaneously, the downregulation of IPO9 was also accompanied by the increased post-translational expression of CFL1. Furthermore, the data obtained in the present study allow us to conclude that CFL1 itself does not translocate actin into the cell nucleus but this transport requires the functional expression of IPO9.

\section{Introduction}

Thousands of women worldwide from all walks of life are diagnosed every day with breast cancer. It is by far the most common cancer among females worldwide and it is also the leading cause of cancer-related mortality (1). Breast cancer is no longer viewed as a single disease since it is heterogeneous consisting of a multitude of subgroups at the molecular, histopathological and clinical level with different prognostic and therapeutic implications. The understanding of the biological mechanisms of breast cancer have elucidated a number of potential therapeutic molecular targets (2). In recent years, specific drugs which modulate these targets in a way that interferes with their ability to promote cancer cell growth or invasion of carcinoma cells have become a part of the standard care of patients with breast cancer (anti-HER2 agents, e.g. trastuzumab and lapatinib). Numerous other agents have not been approved for clinical practice, yet their potential utility is currently under extensive investigation (3-5). In this context, one of the potential candidates appears to be agents that target the actin cytoskeleton of cancer cells or regulate actin cytoskeleton dynamics $(6,7)$.

Numerous studies have indicated that F-actin participates in the induction of cell death and apoptosis. It is known that both cytoplasmic and nuclear actin pools and their proper balance are necessary to maintain cellular homeostasis (8). Translocation of actin between the cytoplasm and the nucleus is not well understood, since this protein does not have a classical nuclear localization signal (9). The transport of actin is possible in association with actin-binding proteins which contain a functional nuclear localization sequence (NLS). Moreover, it has been shown that the export of actin is mediated 
by exportin 6 (XPO6) and imported by importin-9 (IPO9). IPO9 was identified in 2012 by Dopie et al (10) as the nuclear import factor for actin. Using RNA interference (RNAi) technique they demonstrated that the level of nuclear actin could be regulated by altering the ratio of protein to promote both export and import of actin. They also suggested that this area of study requires further elucidation (10). It has also been shown that cofilin (CFL) participates in the transport of actin between the cytoplasm and the nucleus. CFL belongs to the actin-binding protein group and promotes the depolymerization of actin filaments (11-13). Three ADF/CFL isoforms, which fulfill a specific function in actin filament reorganization and possess NLS have been identified in mammalian cells $(11,14)$. Although CFL participates in the active transport of actin to the nucleus under physiological conditions, the mechanism is still unclear (13).

Naturally occurring compounds, particularly those from dietary sources, have recently gained increased scientific attention as potential anticancer drugs and, in particular, as a partner for conventional cytostatic drugs. Garlic, Allium sativum L. is a member of the Alliaceae family, which may have anticarcinogenic effects inter alia by the inhibition of growth and invasive potential of cancer cells and induction of apoptosis (15-18). Such antitumor actions of this vegetable have been attributed to the presence of organosulfur compounds, among which the most abundant in intact garlic is S-allyl-L-cysteine sulfoxide (alliin) (19). Once garlic is processed by cutting or crushing, alliin is rapidly converted to allicin and further into hundreds of di-, tri-, and polysulfides (20). Importantly, it has been shown that some of these metabolites retain anticancer activity comparable to the parent compound or even may be more toxic toward tumor cells $(18,19)$.

Paclitaxel (PTX) is one of the most widely used and effective anticancer agents derived from natural sources (21). Its anticancer activity is associated with binding to tubulin and stabilization of microtubules, resulting in the inhibition of cell division. Additionally, this cytostatic drug induces apoptosis by the mitochondrial pathway and inhibits the function of the apoptosis inhibitor protein B-cell leukemia 2 (Bcl-2) (22). In the present study, the apoptosis in MCF-7 cells was induced by PTX and enhanced by the combined treatment with PTX and garlic-derived alliin.

The aim of present study was to study the impact of the altered actin transport between the cytoplasm and the nucleus by the downregulation of IPO9 in breast adenocarcinoma MCF-7 cells exposed to an apoptosis-inducing combination of PTX and garlic-derived alliin. In the present study, we also investigated whether IPO9 influences the post-translational expression of cofilin-1 (CFL1) and confirmed that CFL1 itself does not influence the nuclear F-actin function in the process of apoptosis.

\section{Materials and methods}

Cell culture and treatment. MCF-7, a human breast adenocarcinoma cell line, was purchased from the American Type Culture Collection (ATCC; Manassas, VA, USA). The cells were grown in tissue culture flasks or 12-well plates (BD Biosciences, Franklin Lakes, NJ, USA) and cultured as a monolayer in Eagle's Minimum Essential Medium (MEM;
Sigma-Aldrich, St. Louis, MO, USA) supplemented with $10 \%$ fetal bovine serum (FBS; Gibco/Invitrogen Life Technologies, Carlsbad, CA, USA) and $50 \mu \mathrm{g} / \mathrm{ml}$ gentamycin (Sigma-Aldrich). The MCF-7 cultures were maintained in $5 \% \mathrm{CO}_{2}$ at $37^{\circ} \mathrm{C}$.

MCF-7 cells were treated with $10 \mu \mathrm{M}$ alliin, 0.1 or $1 \mu \mathrm{M}$ PTX (both from Sigma-Aldrich) and the combination of these agents $(10 \mu \mathrm{M}$ alliin/ $0.1 \mu \mathrm{M}$ PTX or $10 \mu \mathrm{M}$ alliin/1 $\mu \mathrm{M}$ PTX) for $24 \mathrm{~h}$. The control cells were cultured under the same conditions but without exposure to these agents.

Transfection by nucleofection. For the nucleofection of MCF-7 cells, the cells were grown to $80-90 \%$ confluency in MEM with FBS, and $50 \mu \mathrm{g} / \mathrm{ml}$ gentamycin. Following trypsinization, the cells $\left(1 \times 10^{6}\right)$ were transfected using the SE Cell Line 4D-Nucleofector ${ }^{\mathrm{TM}} \mathrm{X}$ kit and 3 pmol siRNA against human IPO9(Hs_IPO9_7; Qiagen, Hilden, Germany) according to the manufacturer's instructions and as previously described (23). For determining the unspecific effects of siRNA transfection, the non-targeting AllStars negative control siRNA (Qiagen) was used. At $72 \mathrm{~h}$ post transfection, the cells were used for the subsequent experiments.

Western blot analysis. Semi-quantitative analysis of the posttranslational expression of IPO9 and CFL1 was performed using western blot analysis. The cells were lysed with RIPA buffer (Sigma-Aldrich). Following normalization of the protein concentration using the BCA protein assay kit (Thermo Scientific Pierce Rockford, IL, USA), equal amounts of protein $(15 \mu \mathrm{g}$ of total protein per lane) were separated using 4-12\% NuPAGE Bis-Tris Gel (Novex/Life Technologies, Carlsbad, CA, USA) and transferred onto nitrocellulose membranes using the iBlot dry western blotting system (Invitrogen/Life Technologies). To determine the position of the protein bands, pre-stained molecular weight markers (Novex/Life Technologies) were used.Next, the membrane was processed using WesternBreeze ${ }^{\circledR}$ chromogenic western blot immunodetection kit by the BenchPro ${ }^{\mathrm{TM}} 4100$ Card Processing Station (both from Invitrogen/Life Technologies) according to the manufacturer's instructions. After that, the membranes were blocked with WesternBreeze ${ }^{\circledR}$ blocking solution for $30 \mathrm{~min}$. The next step was incubation with the primary rabbit monoclonal anti-importin-9 (1:1,000; Abcam, Cambridge, MA, USA), rabbit anti-cofilin-1 $(1: 1,000)$ or rabbit polyclonal anti-GADPH (1:2,000; both from Sigma-Aldrich) antibodies for $2 \mathrm{~h}$ at room temperature (RT) and the membrane washing. After that, membranes were incubated for $1 \mathrm{~h}$ at RT with a ready-to-use solution of alkaline phosphatase-conjugated antispecies IgG. The immunoreactive bands were visualized using a ready-to-use solution of BCIP/NBT substrate for alkaline phosphatase. After scanning, the densitometry of the bands was quantified using Quantity One Basic software (ver. 3.6.5; Bio-Rad, Hercules, CA, USA).

Cell death analysis. The analysis of cell death was carried out using a Tali ${ }^{\circledR}$ image-based cytometer and Tali ${ }^{\circledR}$ apoptosis kit (both from Invitrogen/Life Technologies) according to the manufacturer's instructions and as previously described (23). The analysis was performed using Tali ${ }^{\circledR}$ image-based cytometer and FCS Express Research Edition software (v.4.03; De Novo Software, Glendale, CA, USA) on the condition that early 

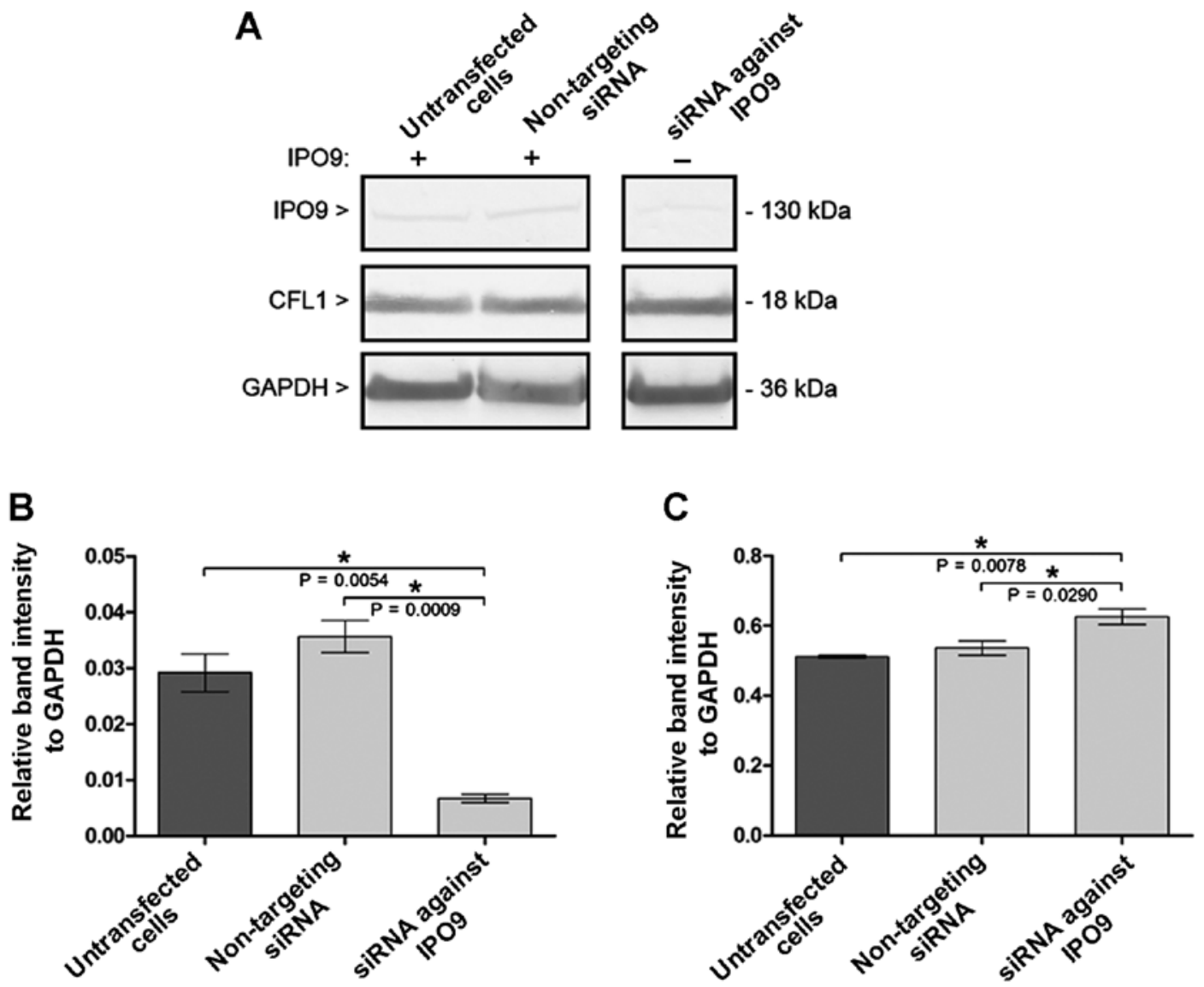

Figure 1. Post-transcriptional expression of importin-9 (IPO9) and cofilin-1 (CLF1) in the MCF-7 cells. (A) Western blot analysis of the post-translational expression of IPO9 and CLF1 in the untransfected MCF-7 cells, cells transfected with non-targeting siRNA and the siRNA against IPO9. (B) Densitometric analysis of IPO9 reactive bands in the untransfected MCF-7 cells, cells transfected with the non-targeting siRNA, and siRNA against IPO9, relative to GADPH. (C) Densitometric analysis of CLF1 reactive bands in the untransfected MCF-7 cells, cells transfected with non-targeting siRNA and siRNA against IPO9, relative to GADPH.

apoptotic cells stain with only Annexin V-Alexa Fluor 488, late apoptotic cells stain with both propidium iodide (PI) and green Annexin V-Alexa Fluor 488, necrotic cells stain with PI, and live cells remain unstained.

Fluorescence staining of F-actin. MCF-7 cells transfected with siRNA-IPO9 and non-targeting AllStars negative control siRNA were seeded on sterile glass coverslips placed in 12-well plates (BD Biosciences). After $24 \mathrm{~h}, \mathrm{PTX}$ (at concentrations of 0.1 and $1 \mu \mathrm{M}$ ) or $10 \mu \mathrm{M}$ alliin were added to the cells for the indicated times as either single or combined agents. Next, the cells were fixed with $4 \%$ paraformaldehyde in PBS for 20 min at RT and stained with phalloidin conjugated to Alexa Fluor 488 (1:40, Invitrogen, Life Technologies, Carlsbad, CA, USA) as previously described (24). Nuclear staining was performed with 4',6'-diamidino-2-phenylindole dihydrochloride (DAPI) (100 ng/ml; Sigma-Aldrich) for $10 \mathrm{~min}$. The cells were examined using an Eclipse E800 fluorescence microscope equipped with a CDD camera (DS-5Mc-U1) and NIS-Elements 3.30 image analysis system (all from Nikon, Tokyo, Japan).

Measurement of F-actin fluorescence intensity. The measurement of fluorescence intensity of F-actin in MCF-7 cells was performed on fluorescent images captured at equal camera settings using ImageJ 1.45s (NIH, Bethesda, MD, USA).
Corrected fluorescence intensity (CFI) of total, cortical or nuclear/perinuclear F-actin was calculated using the following formula: $\mathrm{CFI}=$ integrated density - (region of interest $\mathrm{x}$ mean fluorescence of background), where integrated density was the area region of interest multiplied by the mean fluorescence intensity of F-actin.

Statistical analysis. Statistical analyses were performed by paired t-test using GraphPad Prism 5.0 (GraphPad Software, La Jolla, CA, USA). The results were considered as significant at $\mathrm{P}<0.05$. The data are presented as mean $\pm \mathrm{SD}$.

\section{Results}

Analysis of post-translational downregulation of importin-9 expression and the associated alteration in cofilin-1 expression. Western blot analysis confirmed that siRNA-IPO9 mediated the downregulation of IPO9 post-translational expression, as compared with that in the untransfected cells or cells transfected with the non-targeting siRNA (Fig. 1A). Densitometric analysis also confirmed the decrease in initial IPO9 post-translational expression in the cells transfected with siRNA-IPO9. Furthermore, no statistically significant differences were observed in the relative IPO9 to GAPDH band intensities between the untransfected cells and cells transfected 

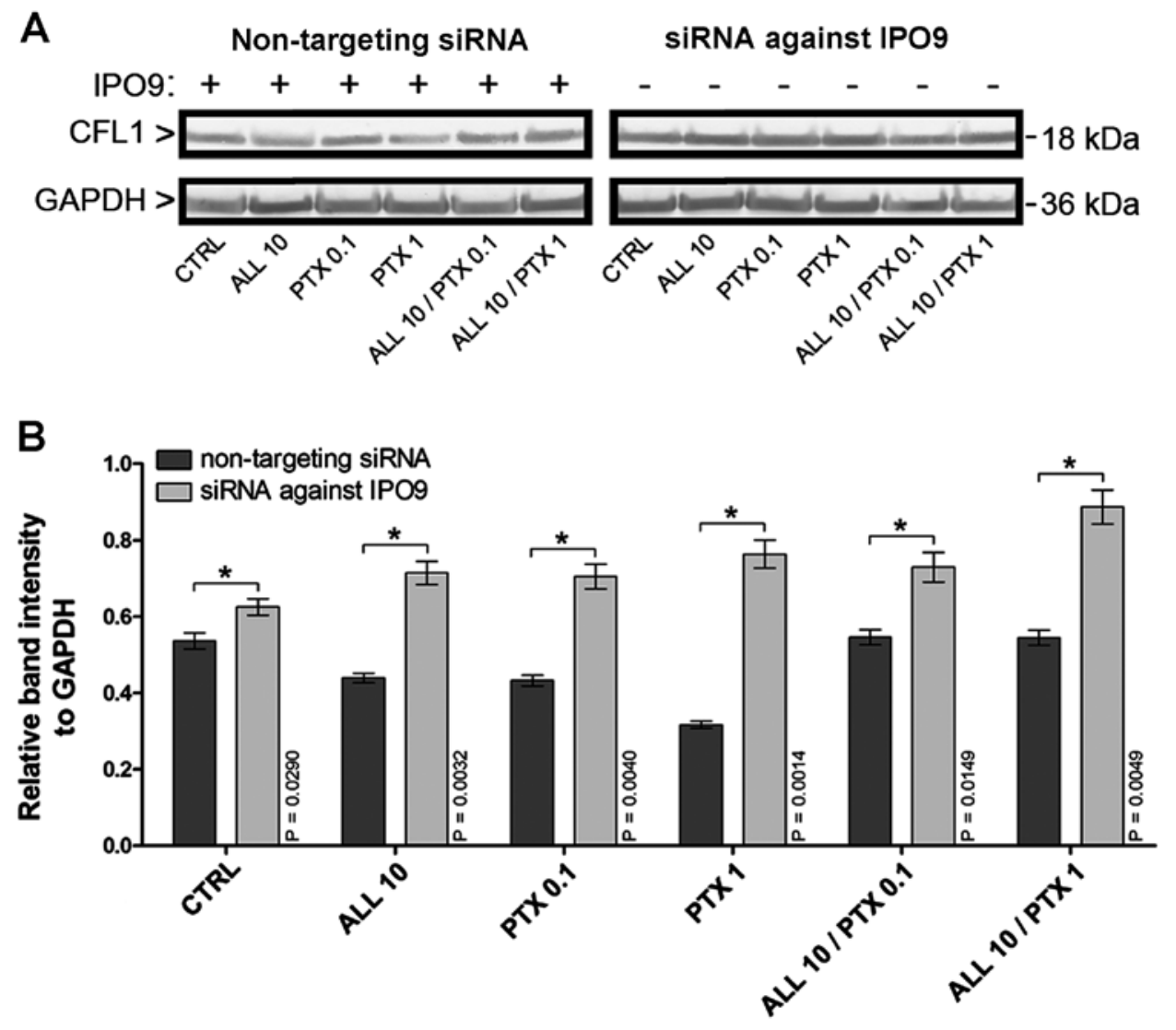

Figure 2. Post-transcriptional expression of cofilin-1 (CFL1) in MCF-7 cells after exposition to garlic-derived alliin (ALL), paclitaxel (PAX) or combination of these agents. (A) Western blot analysis of post-translational expression of CFL1 in the MCF-7 cell line transfected with non-targeting siRNA and siRNA against importin-9 (IPO9) after treatment of cells with ALL, PAX and combination of these agents. (B) Densitometric analysis of CFL1 expression in the MCF-7 cell line transfected with non-targeting siRNA and siRNA against IPO9 after treatment of cells with ALL, PAX and combination of these agents, relative to GADPH. CTRL, control; ALL 10, $10 \mu \mathrm{M}$ alliin; PTX 0.1, $0.1 \mu \mathrm{M}$ paclitaxel; PTX 1, $1 \mu \mathrm{M}$ paclitaxel.

with non-targeting siRNA (Fig. 1B). As shown in Fig. 1B, the transfection of the MCF-7 cells with siRNA-IPO9 induced a statistically significant reduction in IPO9 (23.10 and $18.91 \%$ of initial expression, as compared to untransfected cells and cells transfected with non-targeting siRNA, respectively) as normalized to GAPDH post-translational expression.

Western blot analysis indicated that siRNA-mediated downregulation of IPO9 increased the post-translational expression of CFL1 (Fig. 1A). Moreover, densitometric analysis also confirmed the increase of the initial CFL1 post-translational expression in the cells transfected with siRNA-IPO9. Furthermore, no statistically significant differences were observed in CFL1 band intensities between the untransfected cells and cells transfected with non-targeting siRNA relative to GADPH (Fig. 1C). As shown in Fig. 1C, the transfection of MCF-7 cells with siRNA-IPO9 resulted in a statistically significant increase in the post-translational expression of CFL-1 (122.31 and $116.59 \%$ of the initial expression, as compared to the untransfected cells and the cells transfected with non-targeting siRNA, respectively) as normalized to GAPDH.

Downregulation of importin-9 induces alterations in cofilin-1 protein levels and F-actin organization in the MCF-7 cells. Western blot analysis showed that the downregulation of IPO9 using siRNA-IPO9 induced alterations in the post-translational
CFL1 expression, even following the treatment of MCF-7 cells with alliin and PTX (Fig. 2A). The densitometric analysis also confirmed the increase of CFL1 post-translational expression in the cells transfected with siRNA-IPO9, as compared to the cells transfected with non-targeting siRNA (Fig. 2B). As depicted in Fig. 2B, the downregulation of IPO9 in the control cells resulted in the increased CFL1 post-translational expression by 1.17 -fold $(\mathrm{P}=0.0290)$, when calculated relatively to GAPDH protein levels, respectively. In the cell populations with downregulated IPO9 and incubated with $10 \mu \mathrm{M}$ alliin, the post-translational CFL1 level was elevated by 1.63 -fold $(\mathrm{P}=0.0032)$. The cells transfected with siRNA-IPO9 and treated with $0.1 \mu \mathrm{M}$ PTX were characterized by a similar increase in the CFL1 protein level (1.63-fold; $\mathrm{P}=0.0040)$. The most elevated CFL1 level was observed after the treatment of the IPO9 downregulated MCF-7 cells with $1 \mu \mathrm{M}$ PTX (2.41fold; $\mathrm{P}=0.0014)$. Furthermore, after exposure of these cells to the combination of $10 \mu \mathrm{M}$ alliin and $0.1 \mu \mathrm{M}$ PTX, the CFL1 protein level was increased by 1.34 -fold $(\mathrm{P}=0.0149)$. After the treatment of the IPO9-downregulated MCF-7 cells with the combination of $10 \mu \mathrm{M}$ alliin and $1 \mu \mathrm{M}$ PTX, a 1.63-fold $(\mathrm{P}=0.0049)$ increase in CFL1 protein content was observed.

Fluorescence labeling of F-actin showed that the downregulation of IPO9 using siRNA-IPO9 induced organizational changes in F-actin in the MCF-7 cells, as compared to the cells transfected with non-targeting siRNA. In the control cells 

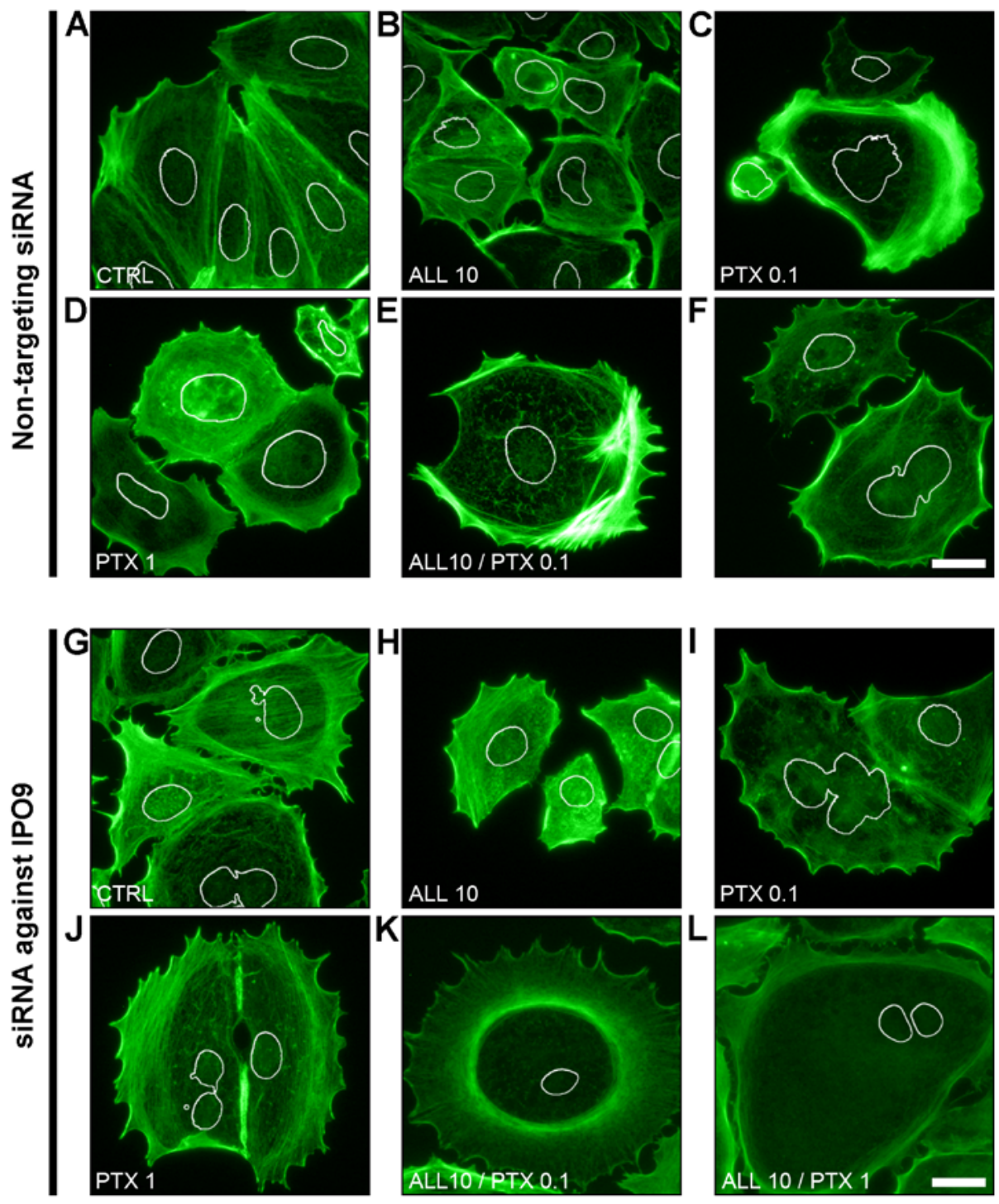

Figure 3. Fluorescence analysis of F-actin organization in MCF-7 cells transfected with non-targeting siRNA and siRNA against importin-9 (IPO9) after exposition to alliin (ALL), paclitaxel (PTX) and the combination of these agents. (A-F) MCF-7 cells transfected with non-targeting siRNA. (G-L) MCF-7 cells transfected with siRNA against IPO9. (A and G) CTRL (control). (B and H) Cells treated with $10 \mu \mathrm{M}$ ALL. (C and I) Cells treated with $0.1 \mu \mathrm{M}$ PTX. (D and J) Cells treated with $1 \mu \mathrm{M}$ PTX. (E and K) Cells treated with combination of $10 \mu \mathrm{M}$ ALL and $0.1 \mu \mathrm{M}$ PTX. (F and L) Cells treated with combination of $10 \mu \mathrm{M}$ ALL and $1 \mu \mathrm{M}$ PTX. ALL 10, $10 \mu \mathrm{M}$ ALL; PTX 0.1, 0.1 $\mu \mathrm{M}$ paclitaxel; PTX 1, $1 \mu \mathrm{M}$ paclitaxel. Scale bar, $20 \mu \mathrm{m}$.

transfected with non-targeting siRNA and the cells treated with $10 \mu \mathrm{M}$ alliin, a voluminous network of tension fibers of actin was observed (Fig. 3A and B). In contrast, the treatment of these cells with $0.1 \mu \mathrm{M}$ PTX resulted in the disorganization of F-actin, which was observed as a diffused fluorescence signal in both the cortical and nuclear/perinuclear areas of the cells (Fig. 3C). Furthermore, after exposure of the cells to $1 \mu \mathrm{M}$ PTX as well as to the combination of $10 \mu \mathrm{M}$ alliin with $0.1 \mu \mathrm{M}$ or $1 \mu \mathrm{M}$ PTX, the nuclear/perinuclear F-actin cytoskeleton was clearly seen as disassembled or in the form of short fibers (Fig. 3D-F). However, the fluorescence labeling of these organizational forms of actin was much higher, as compared to the control cells and the cells treated with $10 \mu \mathrm{M}$ alliin or $0.1 \mu \mathrm{M}$ PTX.

Similar to the cells transfected with non-targeting siRNA, after the induction of IPO9 downregulation, the F-actin of the control cells was also organized in the form of tension fibers (Fig. 3G). However, the downregulation of IPO9 was accompanied by increased cortical actin staining. Furthermore, the treatment of siRNA-IPO9-transfected MCF-7 cells with $10 \mu \mathrm{M}$ alliin or $0.1 \mu \mathrm{M}$ PTX did not reveal any significant differences in F-actin organization, as compared to cells transfected with the non-targeting siRNA (Fig. $3 \mathrm{H}$ and I). In contrast, treatment of these cells with $1 \mu \mathrm{M}$ PTX or the combination of $10 \mu \mathrm{M}$ alliin with $0.1 \mu \mathrm{M}$ or $1 \mu \mathrm{M}$ PTX resulted in a gradual disassembly of both the cortical and nuclear/perinuclear F-actin cytoskeleton (Fig. 3J-L).

Downregulation of importin-9 reduces the apoptotic response of MCF-7 cells to PTX and alliin which is correlated with disassembly of nuclear/perinuclear F-actin cytoskeleton. The quantitative analysis of cell death was performed using Tali Image-based cytometer after Annexin V-Alexa Fluor 488 and PI double staining. As shown in Fig. 4A and Table I, after the treatment of the MCF-7 cells transfected with non-targeting siRNA with $10 \mu \mathrm{M}$ alliin or $0.1 \mu \mathrm{M}$ PTX, no statistically 
A

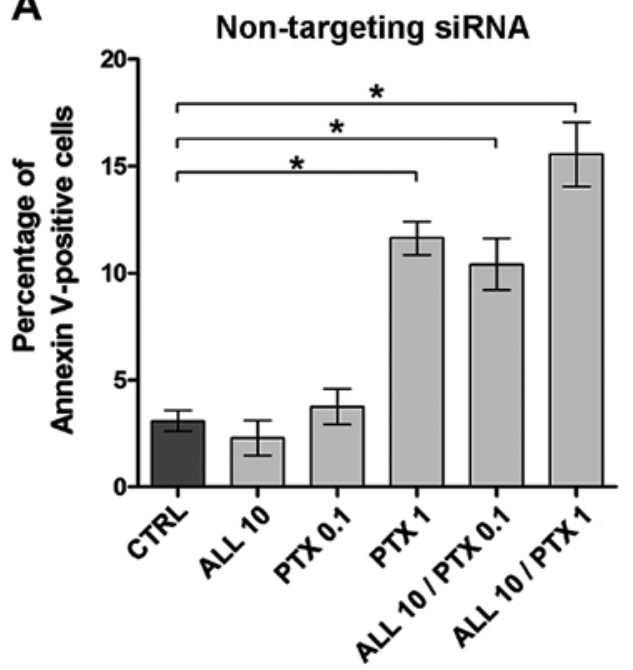

B

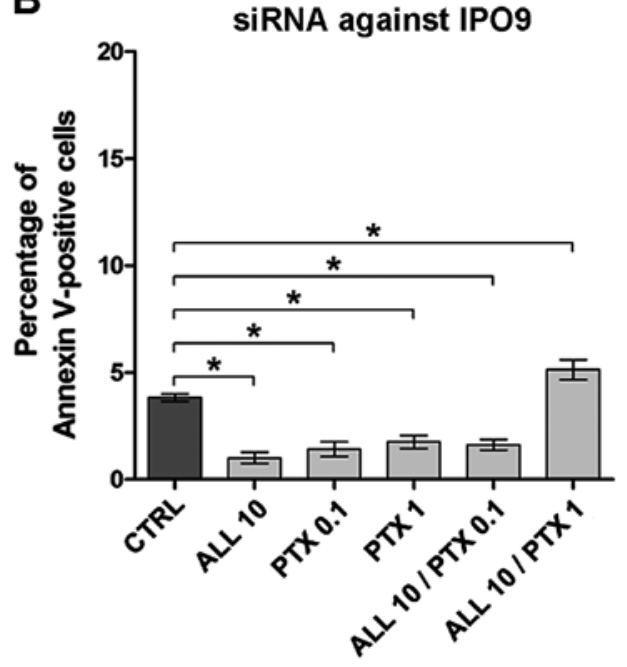

C

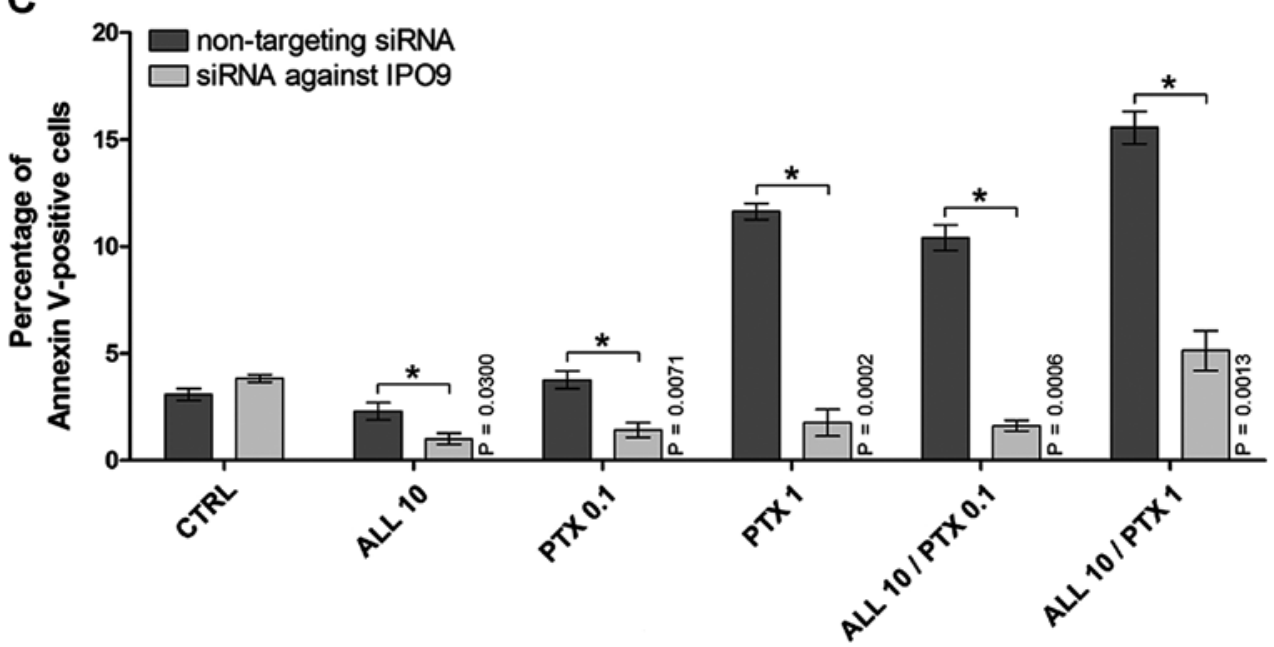

Figure 4. Quantitative analysis of apoptosis in the MCF-7 cells transfected with non-targeting siRNA and siRNA against importin-9 (IPO9) after exposition to alliin (ALL), paclitaxel (PTX) and the combination of these agents. (A) Cells transfected with non-targeting siRNA. (B) Cells transfected with siRNA against IPO9. (C) Comparison of the percentages of Annexin V-positive cells transfected with non-targeting siRNA or siRNA against IPO9, and treated with ALL, PTX and the combination of these agents. CTRL, control; ALL 10, $10 \mu \mathrm{M}$ alliin; PTX 0.1, $0.1 \mu \mathrm{M}$ paclitaxel; PTX 1, $1 \mu \mathrm{M}$ paclitaxel.

Table I. P-values of changes in the percentage of Annexin V-positive MCF-7 cells transfected with non-targeting siRNA in response to garlic-derived alliin, paclitaxel or combination of these agents.

$\begin{array}{lllll}\text { CTRL } & \text { ALL } 10 & \text { PTX } 0.1 & \text { PTX } 1 & \text { ALL 10/PTX } 0.1\end{array}$

ALL 10/PTX 1

\section{CTRL}

ALL 10

PTX 0.1

PTX 1

ALL 10/PTX 0.1

ALL 10/PTX 1

$\begin{array}{cc}\mathrm{NS} & - \\ \mathrm{NS} & \mathrm{P}=0.0042 \\ \mathrm{P}=0.0016 & \mathrm{P}=0.0147 \\ \mathrm{P}=0.0005 & \mathrm{P}=0.0006 \\ \mathrm{P}=0.0014 & \mathrm{P}=0.0006\end{array}$

PTX 0.1
ALL 10/PTX 0.1

NS, non-statistically significant; CTRL, control; ALL 10, $10 \mu \mathrm{M}$ alliin; PTX 0.1, 0.1 $\mu \mathrm{M}$ paclitaxel; PTX 1, $1 \mu \mathrm{M}$ paclitaxel.

significant differences were found in the percentage of Annexin V-positive cells. However, after exposure of these cells to $1 \mu \mathrm{M}$ PTX, the percentage of Annexin V-positive cells increased by 3.78 -fold $(\mathrm{P}=0.0016)$. Furthermore, when the cells transfected with non-targeting siRNA were treated with the combinations of alliin and PTX, the percentage of Annexin V-positive cells was increased by 3.38 -fold $(\mathrm{P}=0.0005)$ and 5.05-fold $(\mathrm{P}=0.0014)$, respectively (Fig. 4A).

In contrast, after exposure of the siRNA-IPO9-transfected cells to $10 \mu \mathrm{M}$ alliin or $0.1 \mu \mathrm{M}$ PTX, statistically significant 
Table II. P-values of changes in the percentage of Annexin V-positive MCF-7 cells transfected with siRNA against importin-9 in response to garlic-derived alliin, paclitaxel or combination of these agents.

\begin{tabular}{lcccccc}
\hline & CTRL & ALL 10 & PTX 0.1 & PTX 1 & ALL 10/PTX 0.1 & ALL 10/PTX 1 \\
\hline CTRL & - & & & & & \\
ALL 10 & $\mathrm{P}<0.0001$ & - & & & \\
PTX 0.1 & $\mathrm{P}=0.0002$ & $\mathrm{P}=0.0172$ & - & & \\
PTX 1 & $\mathrm{P}=0.0067$ & $\mathrm{P}=0.0443$ & NS & - & - & - \\
ALL 10/PTX 0.1 & $\mathrm{P}<0.0001$ & $\mathrm{P}=0.0049$ & NS & NS & $\mathrm{P}=0.0037$ & - \\
ALL 10/PTX 1 & $\mathrm{P}=0.0389$ & $\mathrm{P}=0.0018$ & $\mathrm{P}=0.0039$ & $\mathrm{P}=0.0137$ & $\mathrm{P}$ & \\
\hline
\end{tabular}

NS, non-statistically significant; CTRL, control; ALL 10, $10 \mu \mathrm{M}$ alliin; PTX 0.1, 0.1 $\mu \mathrm{M}$ paclitaxel; PTX 1, $1 \mu \mathrm{M}$ paclitaxel.

differences in the percentages of Annexin V-positive cells were noted, as compared to the control. As shown in Fig. 4B and Table II, a decrease in the Annexin V-positive cell percentages after the treatment with $10 \mu \mathrm{M}$ alliin or $0.1 \mu \mathrm{M}$ PTX by 3.84fold $(\mathrm{P}<0.0001)$ or 2.71 -fold $(\mathrm{P}=0.0002)$, respectively, was noted. Similar, exposure of the cells with downregulated IPO9 to $1 \mu \mathrm{M}$ PTX resulted in a 2.18 -fold $(\mathrm{P}=0.0067)$ reduction in Annexin V-positive cells. The treatment of these cells with the combination of $10 \mu \mathrm{M}$ alliin and $0.1 \mu \mathrm{M}$ PTX decreased the population of Annexin V-positive cells by 2.36-fold $(\mathrm{P}<0.0001)$. However, a 1.34-fold $(\mathrm{P}=0.0389)$ increase in the percentage of Annexin $\mathrm{V}$-positive cells was observed after treatment of the IPO9-downregulated cells with the combination of $10 \mu \mathrm{M}$ alliin and $1 \mu \mathrm{MPTX}$ (Fig. 4B). Moreover, comparison of the percentages of Annexin V-positive cells transfected with non-targeting siRNA and siRNA-IPO9 showed a statistically significant reduction in apoptosis after downregulation of IPO9 and the treatment of the cells with alliin, PTX or combination of these agents. As shown in Fig. 4C, the silencing of IPO9 decreased the percentage of Annexin V-positive cells after treatment with $10 \mu \mathrm{M}$ alliin (2.30-fold, $\mathrm{P}=0.0300), 0.1 \mu \mathrm{M}$ PTX (2.66-fold, $\mathrm{P}=0.0071$ ), $1 \mu \mathrm{M}$ PTX (6.61-fold, $\mathrm{P}=0.0002)$, and after exposure of MCF-7 cells to the combination of $10 \mu \mathrm{M}$ alliin and 0.1 or $1 \mu \mathrm{M}$ PTX (6.41-fold, $\mathrm{P}=0.0006$; or 3.03-fold, $\mathrm{P}=0.0013$ ), as compared to the cells expressing IPO9. Furthermore, a $>8 \%$ reduction in Annexin V-positive cells was correlated with a decrease in F-actin content measured in whole cells, as well as in the cortical and nuclear/perinuclear area of cells. This, was clearly noted after the treatment of cells with $1 \mu \mathrm{M}$ PTX (reduction of 4.69-fold, $\mathrm{P}=0.0392$; 5.35-fold, $\mathrm{P}=0.0368$; and 1.91-fold, $\mathrm{P}=0.0337$, respectively), the combination of $10 \mu \mathrm{M}$ alliin and 0.1 PTX (reduction of 16.02-fold; 20.46-fold; and 4.82-fold, $\mathrm{P}=0.0179$, respectively) or the combination of $10 \mu \mathrm{M}$ alliin and $1 \mu \mathrm{M}$ PTX (reduction of 3.89-fold, 2.61-fold and 7.71-fold, $\mathrm{P}=0.0286$, respectively) (Fig. 5A-C). The data presented here suggest that the altered import of F-actin into the nucleus prevents apoptotic cell death.

\section{Discussion}

Many authors have shown that the human breast adenocarcinoma MCF-7 cell line may be useful for in vitro breast cancer research (24-26). It is known that breast cancer is one of the most common cancers among females worldwide and its treatment is difficult (1). Therefore, new therapeutic strategies, including the targeted silencing of gene expression using e.g. RNAi technique have recently been developed to induce apoptosis directly or inhibit intracellular pro-survival signaling pathways and angiogenesis as well (27). The list of promising targeted agents against breast cancer includes tyrosine kinase inhibitors (TKIs), inhibitors of the PI3K/AKT/mTOR pathway and agents that interfere with DNA repair (28). Furthermore, Foerster et al (6) suggested that the actin cytoskeleton can be used as a target for breast cancer therapy. The actin cytoskeleton is a structure regulated by many proteins, including actin binding proteins, Rho GTPases, kinase C- $\varepsilon$, which offer unlimited potential for the development of anticancer treatment strategies $(6,29,30)$.

Research has shown that natural dietary agents, either alone or in combination with chemotherapeutic agents, have the potential to prevent the occurrence and/or spread of cancer (31-33). The mechanisms leading to the induction of apoptosis by garlic derivatives have been described in a number of cancer cell lines, including the MCF-7 human breast cancer cell line $(15,34)$. Moreover, the potentiation of the cytotoxic effects of traditional cytostatic drugs by sulfur-containing compounds of garlic has also been documented in vitro (35). In the present study, we used alliin to enhance the apoptotic effect of PTX. The study verified the alliin-mediated potentiation of apoptosis induced by PTX. The results presented in the present study support the potentiation of the cytotoxic effects of traditional cytostatic drugs by sulfur-containing compounds of garlic and indicate that alliin and PTX act synergistically to promote apoptosis in MCF-7 cells.

A large body of literature has shown the nuclear localization of actin $(10,23,36-38)$. In the nucleus, actin is involved indirectly in transcription, since it is associated with all three RNA polymerases (Pol I, II and III) $(39,40)$. Percipalle et al (41) found that through the interaction with RNA polymerase II nuclear actin is involved in transcription processes of Balbiani rings. Actin has also been described as a component of the BAF complex and ATP-dependent chromatin remodeling complex SWR1 (42-45). Furthermore, Cisterna et al (46) postulated that actin can also be located in nucleoli where it participates in the transport of small ribosomal subunits to the cytoplasm. Although significant progress in this field has been made in recent years, research is still investigating new 

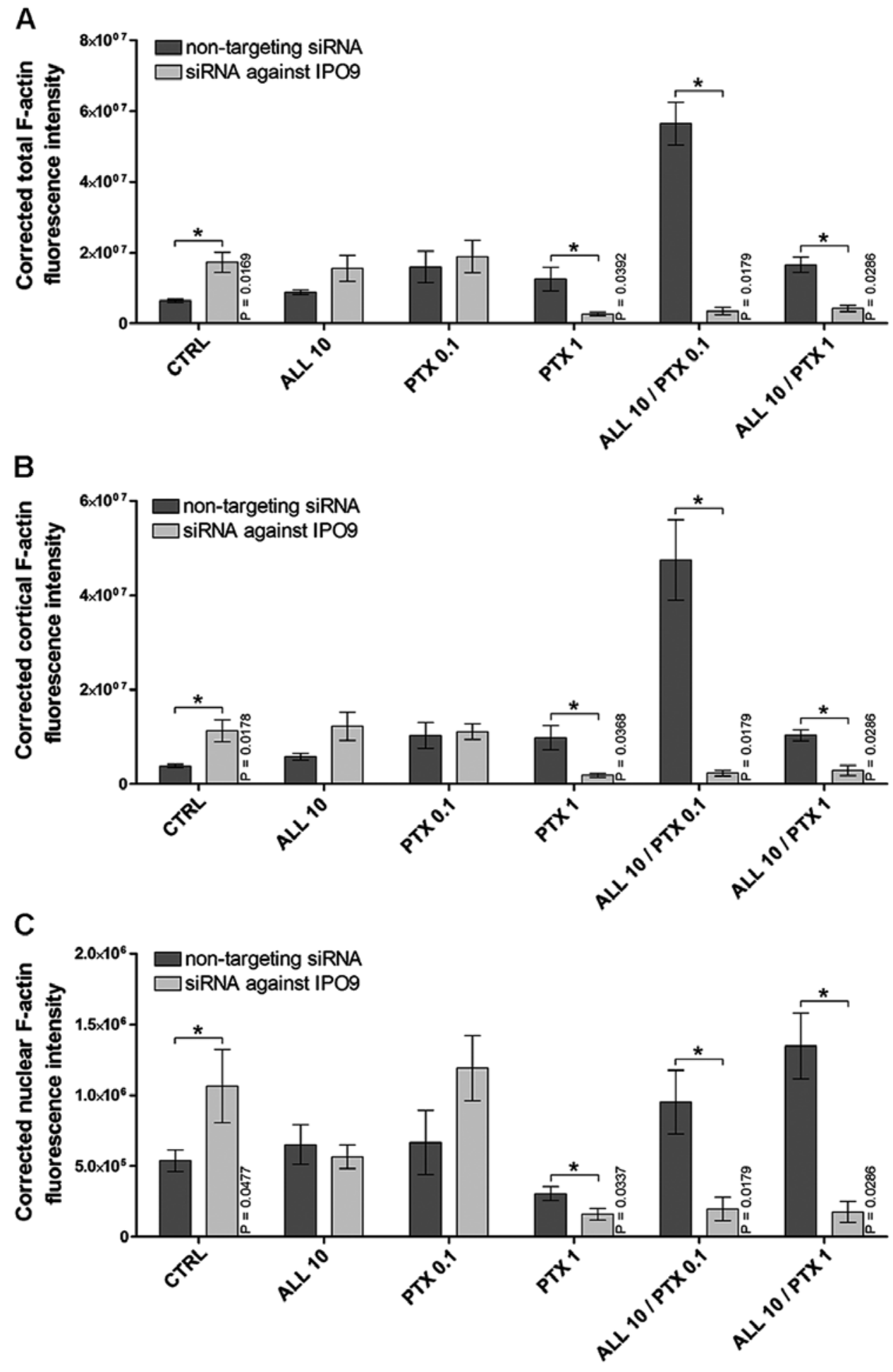

Figure 5. Fluorescence intensity of F-actin in the MCF-7 cells transfected with non-targeting siRNA and siRNA against importin-9 (IPO9) after exposition to alliin (ALL), paclitaxel (PTX) and the combination of these agents. (A) Corrected fluorescence of total F-actin. (B) Corrected fluorescence of cortical F-actin. (C) Corrected fluorescence of nuclear F-actin. CTRL, control; ALL 10, $10 \mu \mathrm{M}$ alliin; PTX 0.1, $0.1 \mu \mathrm{M}$ paclitaxel; PTX 1, $1 \mu \mathrm{M}$ paclitaxel.

nuclear functions of actin and the molecular mechanisms by which actin functions within the nucleus but also the tools that enable us to manipulate nuclear actin concentrations without perturbing cytoplasmic actin (47). In addition, finally, we are interested in whether such a manipulation may be employed as a novel approach for the treatment of cancers, in particular, those that are currently incurable.
Our previous studies demonstrated not only the translocation of actin into the nucleus but also the involvement of nuclear F-actin in chromatin remodeling during death processes of different cell lines $(23,38)$. Hofmann et al (9) suggested that nuclear actin may be translocated from the cytoplasm into the nucleus, but it does not have a classical nuclear localization signal itself. However, the transport of actin is possible by 
its association with actin-binding proteins which contain a functional NLS (13). As it has been shown, the export of actin is mediated by XPO6 and the import by IPO9. However, the mechanisms of actin translocation between the cytoplasm and nucleus require further investigation. In the present study, we showed that the downregulation of IPO9 using siRNA-IPO9 induced alterations in post-translational CFL1 expression, even after the treatment of MCF-7 cells with the combination of alliin and PTX. Pendleton et al (48) showed that during stress conditions actin is transported into the nucleus in a complex with actin-binding proteins such as CFL which contains the NLS. In contrast, the involvement of CFL in actin transport under physiological conditions is not clear. Huet et al (49) revealed that IPO9 interacted both with actin and CFL in a co-immunoprecipitation experiment, and hypothesized that actin enters into the nucleus in a complex with IPO9 and CFL. In the present study to ascertain whether downregulation of IPO9 induces alterations in the post-translational expression of NLS-containing proteins, the post-translational level of CFL1 was investigated. In the present study, we confirmed that downregulation of IPO9 increased the post-translational expression of CFL1.

Our previous studies showed that CFL1 mediates apoptosis in response to stress conditions (50). Similarly, Huot et al (51) observed actin at the border of the apoptotic blebs whereas Levee et al (52) revealed its accumulation in the area of apoptotic body formation and suggested that the reorganization of the F-actin network is essential for this process. Furthermore, Chua et al (53) demonstrated that CFL has an important function during the initial phase of apoptosis. Moreover, oxidant-induced apoptosis and mitochondrial integrity can be regulated through oxidation of CFL (54). We also demonstrated that doxorubicin treatment of $\mathrm{CHO}$ AA8 cells with the functional expression of CFL1 induced both apoptosis and mitotic catastrophe as the main types of cell death. In contrast, the downregulation of CFL1 preferentially induced mitotic catastrophe as doxorubicin-induced cell death (50). We also showed that the presence of actin is important for induction of active cell death (23). Furthermore, we observed an increase in nuclear F-actin labeling after the induction of CFL1 expression in MCF-7 cells. Vartiainen (13) suggested that such an effect was possibly associated with the involvement of CFL1 in the transport of actin monomers to the cell nucleus and their reassembly into short polymers. In the present study, we showed a significant reduction in both cortical and nuclear F-actin fluorescence in cells with downregulated expression of IPO9 after treatment of cells with a high dose of PTX as well as the combination of PTX and alliin. Similarly, the downregulation of IPO9 resulted in significant reduction in apoptosis induced by PTX, allin or a high apoptosis-inducing combination of PTX and alliin. These data suggest that CFL1 itself does not translocate actin into the cell nucleus but this transport requires the functional expression of IPO9.

In conclusion, the results presented here showed that alliin and PTX act synergistically to promote apoptosis in MCF-7 cells and support the potentiation of the cytotoxic effects of traditional cytostatic drugs by sulfur-containing compounds of garlic. As it has been shown by many authors, actin may translocate into the cell nucleus to function as a transcriptional modulator of gene expression (47,55-58). Our previous studies demonstrated not only the translocation of F-actin into the nucleus but also its involvement in chromatin remodeling during cell death processes $(23,38,50,59,60)$. In the present study, we revealed that the downregulation of IPO 9 correlates with the significant reduction in the apoptotic cell population as well as with the decrease in F-actin content in whole cells, and in cortical and nuclear/perinuclear areas of MCF-7 cells. Simultaneously, the downregulation of IPO9 was also accompanied by the increased post-translational expression of CFL1. Therefore, the obtained data suggest that CFL1 itself does not translocate actin into the cell nucleus but this transport requires the functional expression of IPO9.

\section{Acknowledgements}

The present study was supported by grant no. MN-5/WL from Nicolaus Copernicus University (NCU).

\section{References}

1. Jemal A, Bray F, Center MM, Ferlay J, Ward E and Forman D: Global cancer statistics. CA Cancer J Clin 61: 69-90, 2011.

2. Carey LA, Perou CM, Livasy CA, Dressler LG, Cowan D, Conway K, Karaca G, Troester MA, Tse CK, Edmiston S, et al: Race, breast cancer subtypes, and survival in the Carolina Breast Cancer Study. JAMA 295: 2492-2502, 2006.

3. Baselga J, Gelmon KA, Verma S, Wardley A, Conte P, Miles D, Bianchi G, Cortes J, McNally VA, Ross GA, et al: Phase II trial of pertuzumab and trastuzumab in patients with human epidermal growth factor receptor 2-positive metastatic breast cancer that progressed during prior trastuzumab therapy. J Clin Oncol 28: 1138-1144, 2010.

4. Tutt A, Robson M, Garber JE, Domchek SM, Audeh MW, Weitzel JN, Friedlander M, Arun B, Loman N, Schmutzler RK, et al: Oral poly(ADP-ribose) polymerase inhibitor olaparib in patients with $B R C A 1$ or BRCA2 mutations and advanced breast cancer: A proof-of-concept trial. Lancet 376: 235-244, 2010.

5. Macaskill EJ, Bartlett JM, Sabine VS, Faratian D, Renshaw L, White S, Campbell FM, Young O, Williams L, Thomas JS, et al: The mammalian target of rapamycin inhibitor everolimus (RAD001) in early breast cancer: Results of a pre-operative study. Breast Cancer Res Treat 128: 725-734, 2011.

6. Foerster F, Braig S, Moser C, Kubisch R, Busse J, Wagner E, Schmoeckel E, Mayr D, Schmitt S, Huettel S, et al: Targeting the actin cytoskeleton: Selective antitumor action via trapping PKC $\varepsilon$. Cell Death Dis 5: e1398, 2014.

7. Groth-Pedersen L, Aits S, Corcelle-Termeau E, Petersen NH, Nylandsted $J$ and Jäättelä M: Identification of cytoskeletonassociated proteins essential for lysosomal stability and survival of human cancer cells. PLoS One 7: e45381, 2012.

8. Dingová H, Fukalová J, Maninová M, Philimonenko VV and Hozák P: Ultrastructural localization of actin and actin-binding proteins in the nucleus. Histochem Cell Biol 131: 425-434, 2009.

9. Hofmann WA, Arduini A, Nicol SM, Camacho CJ, Lessard JL, Fuller-Pace FV and de Lanerolle P: SUMOylation of nuclear actin. J Cell Biol 186: 193-200, 2009.

10. Dopie J, Skarp KP, Rajakylä EK, Tanhuanpää K and Vartiainen MK: Active maintenance of nuclear actin by importin 9 supports transcription. Proc Natl Acad Sci USA 109: E544-E552, 2012.

11. Bamburg JR and Wiggan OP: ADF/cofilin and actin dynamics in disease. Trends Cell Biol 12: 598-605, 2002.

12. Theriot JA: Accelerating on a treadmill: ADF/cofilin promotes rapid actin filament turnover in the dynamic cytoskeleton. J Cell Biol 136: 1165-1168, 1997.

13. Vartiainen MK: Nuclear actin dynamics-from form to function. FEBS Lett 582: 2033-2040, 2008.

14. Vartiainen MK, Mustonen T, Mattila PK, Ojala PJ, Thesleff I, Partanen $\mathbf{J}$ and Lappalainen P: The three mouse actin-depolymerizing factor/cofilins evolved to fulfill cell-type-specific requirements for actin dynamics. Mol Biol Cell 13: 183-194, 2002. 
15. Oommen S, Anto RJ, Srinivas G and Karunagaran D: Allicin (from garlic) induces caspase-mediated apoptosis in cancer cells. Eur J Pharmacol 485: 97-103, 2004.

16. Xu B, Monsarrat B, Gairin JE and Girbal-Neuhauser E: Effect of ajoene, a natural antitumor small molecule, on human $20 \mathrm{~S}$ proteasome activity in vitro and in human leukemic HL60 cells. Fundam Clin Pharmacol 18: 171-180, 2004.

17. Vinay K and Singh DK: Pharmacological effects of garlic (Allium sativum L.). ARBS 10: 6-26, 2008.

18. Chu Q, Ling MT, Feng H, Cheung HW, Tsao SW, Wang X and Wong YC: A novel anticancer effect of garlic derivatives: Inhibition of cancer cell invasion through restoration of E-cadherin expression. Carcinogenesis 27: 2180-2189, 2006.

19. Omar SH and Al-Wabel NA: Organosulfur compounds and possible mechanism of garlic in cancer. Saudi Pharm J 18: 51-58, 2010.

20. Kelkel M,Cerella C,Mack F,SchneiderT,JacobC,Schumacher M, Dicato $\mathrm{M}$ and Diederich M: ROS-independent JNK activation and multisite phosphorylation of Bcl-2 link diallyl tetrasulfideinduced mitotic arrest to apoptosis. Carcinogenesis 33: 2162-2171, 2012.

21. Surapaneni MS, Das SK and Das NG: Designing paclitaxel drug delivery systems aimed at improved patient outcomes: Current status and challenges. ISRN Pharmacol 2012: 623139, 2012.

22. Barbuti AM and Chen ZS: Paclitaxel through the ages of anticancer therapy: Exploring its role in chemoresistance and radiation therapy. Cancers 7: 2360-2371, 2015.

23. Grzanka D, Izdebska M, Klimaszewska-Wisniewska A and Gagat M: The alterations in SATB1 and nuclear F-actin expression affect apoptotic response of the MCF-7 cells to geldanamycin. Folia Histochem Cytobiol 53: 79-87, 2015.

24. Lamparska-Przybysz M, Gajkowska B and Motyl T: BID-deficient breast cancer MCF-7 cells as a model for the study of autophagy in cancer therapy. Autophagy 2: 47-48, 2006.

25. Bullinger D, Neubauer H, Fehm T, Laufer S, Gleiter $\mathrm{CH}$ and Kammerer B: Metabolic signature of breast cancer cell line MCF-7: Profiling of modified nucleosides via LC-IT MS coupling. BMC Biochem 8: 25, 2007.

26. Holliday DL and Speirs V: Choosing the right cell line for breast cancer research. Breast Cancer Res 13: 215, 2011.

27. Schlotter CM, Vogt U, Allgayer H and Brandt B: Molecular targeted therapies for breast cancer treatment. Breast Cancer Res 10: 211, 2008.

28. Higgins MJ and Baselga J: Targeted therapies for breast cancer. J Clin Invest 121: 3797-3803, 2011

29. dos Remedios CG, Chhabra D, Kekic M, Dedova IV, Tsubakihara M, Berry DA and Nosworthy NJ: Actin binding proteins: Regulation of cytoskeletal microfilaments. Physio Rev 83: 433-473, 2003

30. Kaibuchi K, Kuroda S and Amano M: Regulation of the cytoskeleton and cell adhesion by the Rho family GTPases in mammalian cells. Annu Rev Biochem 68: 459-486, 1999.

31. Surh YJ: Cancer chemoprevention with dietary phytochemicals. Nat Rev Cancer 3: 768-780, 2003.

32. Khan N, Afaq F and Mukhtar H: Cancer chemoprevention through dietary antioxidants: Progress and promise. Antioxid Redox Signal 10: 475-510, 2008.

33. Mukhtar E, Adhami VM, Khan N and Mukhtar H: Apoptosis and autophagy induction as mechanism of cancer prevention by naturally occurring dietary agents. Curr Drug Targets 13 1831-1841, 2012

34. Na HK, Kim EH, Choi MA, Park JM, Kim DH and Surh YJ: Diallyl trisulfide induces apoptosis in human breast cancer cells through ROS-mediated activation of JNK and AP-1. Biochem Pharmacol 84: 1241-1250, 2012.

35. Howard EW, Lee DT, Chiu YT, Chua CW, Wang X and Wong YC: Evidence of a novel docetaxel sensitizer, garlic-derived $\mathrm{S}$-allylmercaptocysteine, as a treatment option for hormone refractory prostate cancer. Int J Cancer 122: 1941-1948, 2008.

36. Grosse R and Vartiainen MK: To be or not to be assembled: Progressing into nuclear actin filaments. Nat Rev Mol Cell Biol 14: 693-697, 2013

37. Kapoor P and Shen X: Mechanisms of nuclear actin in chromatinremodeling complexes. Trends Cell Biol 24: 238-246, 2014

38. Grzanka D, Gagat $M$ and Izdebska M: Involvement of the SATB1/F-actin complex in chromatin reorganization during active cell death. Int J Mol Med 33: 1441-1450, 2014.
39. $\mathrm{Hu} \mathrm{P}, \mathrm{Wu} \mathrm{S}$ and Hernandez $\mathrm{N}$ : A role for beta-actin in RNA polymerase III transcription. Genes Dev 18: 3010-3015, 2004.

40. Fomproix $\mathrm{N}$ and Percipalle P: An actin-myosin complex on actively transcribing genes. Exp Cell Res 294: 140-148, 2004.

41. Percipalle P, Zhao J, Pope B, Weeds A, Lindberg U and Daneholt B: Actin bound to the heterogeneous nuclear ribonucleoprotein hrp36 is associated with Balbiani ring mRNA from the gene to polysomes. J Cell Biol 153: 229-236, 2001.

42. Zhao K, Wang W, Rando OJ, Xue Y, Swiderek K, Kuo A and Crabtree GR: Rapid and phosphoinositol-dependent binding of the SWI/SNF-like BAF complex to chromatin after T lymphocyte receptor signaling. Cell 95: 625-636, 1998.

43. Rando OJ, Zhao K, Janmey P and Crabtree GR: Phosphatidylinositol-dependent actin filament binding by the SWI/ SNF-like BAF chromatin remodeling complex. Proc Natl Acad Sci USA 99: 2824-2829, 2002.

44. Morrison AJ and Shen X: Chromatin remodelling beyond transcription: The INO80 and SWR1 complexes. Nat Rev Mol Cell Biol 10: 373-384, 2009.

45. Bogolyubova I: F-actin distribution pattern in the nuclei of early mouse embryos. Folia Histochem Cytobiol 47: 461-463, 2009.

46. Cisterna B, Necchi D, Prosperi E and Biggiogera M: Small ribosomal subunits associate with nuclear myosin and actin in transit to the nuclear pores. FASEB J 20: 1901-1903, 2006.

47. Olave IA, Reck-Peterson SL and Crabtree GR: Nuclear actin and actin-related proteins in chromatin remodeling. Annu Rev Biochem 71: 755-781, 2002.

48. Pendleton A, Pope B, Weeds A and Koffer A: Latrunculin B or ATP depletion induces cofilin-dependent translocation of actin into nuclei of mast cells. J Biol Chem 278: 14394-14400, 2003.

49. Huet G, Rajakylä EK, Viita T, Skarp KP, Crivaro M, Dopie J and Vartiainen MK: Actin-regulated feedback loop based on Phactr4, PP1 and cofilin maintains the actin monomer pool. J Cell Sci 126: 497-507, 2013.

50. Grzanka D, Marszałek A, Gagat M, Izdebska M, Gackowska L and Grzanka A: Doxorubicin-induced F-actin reorganization in cofilin-1 (nonmuscle) down-regulated CHO AA8 cells. Folia Histochem Cytobiol 48: 377-386, 2010.

51. Huot J, Houle F, Rousseau S, Deschesnes RG, Shah GM and Landry J: SAPK $2 / \mathrm{p} 38$-dependent F-actin reorganization regulates early membrane blebbing during stress-induced apoptosis. J Cell Biol 143: 1361-1373, 1998.

52. Levee MG, Dabrowska MI, Lelli JL Jr and Hinshaw DB: Actin polymerization and depolymerization during apoptosis in HL-60 cells. Am J Physiol 271: C1981-C1992, 1996.

53. Chua BT, Volbracht C, Tan KO, Li R, Yu VC and Li P: Mitochondrial translocation of cofilin is an early step in apoptosis induction. Nat Cell Biol 5: 1083-1089, 2003.

54. Klamt F, Zdanov S, Levine RL, Pariser A, Zhang Y, Zhang B, Yu LR, Veenstra TD and Shacter E: Oxidant-induced apoptosis is mediated by oxidation of the actin-regulatory protein cofilin. Nat Cell Biol 11: 1241-1246, 2009.

55. Gieni RS and Hendzel MJ: Actin dynamics and functions in the interphase nucleus: Moving toward an understanding of nuclear polymeric actin. Biochem Cell Biol 87: 283-306, 2009.

56. Louvet $\mathrm{E}$ and Percipalle P: Transcriptional control of gene expression by actin and myosin. Int Rev Cell Mol Biol 272: 107-147, 2009.

57. Qi T, Tang W, Wang L, Zhai L, Guo L and Zeng X: G-actin participates in RNA polymerase II-dependent transcription elongation by recruiting positive transcription elongation factor $\mathrm{b}$ (P-TEFb). J Biol Chem 286: 15171-15181, 2011.

58. Aoyama K, Yuki R, Horiike Y, Kubota S, Yamaguchi N, Morii M, Ishibashi K, Nakayama Y, Kuga T, Hashimoto Y, et al: Formation of long and winding nuclear F-actin bundles by nuclear c-Abl tyrosine kinase. Exp Cell Res 319: 3251-3268, 2013.

59. Izdebska M, Grzanka D, Gagat M, Gackowska L and Grzanka A: The effect of G-CSF on F-actin reorganization in HL-60 and K562 cell lines. Oncol Rep 28: 2138-2148, 2012.

60. Izdebska M, Gagat M, Grzanka D and Grzanka A: Ultrastructural localization of $\mathrm{F}$-actin using phalloidin and quantum dots in HL-60 promyelocytic leukemia cell line after cell death induction by arsenic trioxide. Acta Histochem 115: 487-495, 2013 